\title{
Aproximações entre trabalho e educação na América Latina e no mundo
}

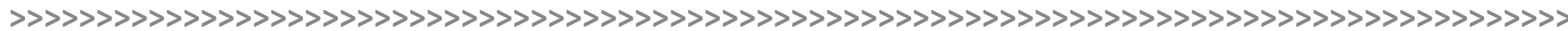

Valter Morigi*

\section{Resumo:}

O artigo trabalha os pontos de convergência entre educação popular, a questão do trabalho e a educação. Parte do histórico do trabalho no capitalismo como conhecemos hoje para afirmar a economia solidária enquanto uma alternativa possível de ser apontada como política pública, numa realidade na qual o trabalho é supervalorizado e todo ócio é condenado.Defende a necessidade de transformação, para que os habitantes das cidades do mundo articulem ações e propostas que permitam melhor fazer frente aos novos desafios do mundo do trabalho, dando a todas as pessoas oportunidades de desenvolvimento e crescimento individual e coletivo.

\section{Palavras-chave:}

Trabalho. Educação. Economia solidária.

\begin{abstract}
:
The article deals with the points of convergence between popular education, the issue of work and education, based on the history of labor in capitalism as we know it today to affirm the solidarity economy as a possible alternative to be identified as public policy a reality in which work is overrated and all entertainment is convicted, advocating the need for transformation, so that the inhabitants of the cities of the world link actions and proposals to better cope with the new challenges of the working world, giving everyone opportunities development and individual and collective growth.
\end{abstract}

\section{Keywords:}

Work. Education. Solidarity Economy.

\section{Introdução}

Hoje os processos educacionais e os processos sociais mais abrangentes de reprodução estão intimamente ligados. Uma reformulação significativa da educação é inconcebível sem a correspondente transformação do quadro social em que as práticas educacionais da sociedade devem cumprir importantes funções de mudança.

O sistema educacional na América Latina está inserido no contexto do sistema global capitalista que se encontra em crise ${ }^{1}$. Para entendermos tal crise e tentar respondê-la é necessária a formação de um projeto político-pedagógico em que a educação popular encontre eco em novas tentativas pedagógicas, como é o caso das Escola Cidadã, das Cidades Educadoras, da Escola da Ponte e outras novidades que encontramos no mundo.

\footnotetext{
* > Mestre e Doutor em Educação, professor de Português da rede estadual do RS (lotado no Colégio Júlio de Castilhos) e da rede municipal de Porto Alegre, atualmente cedido à Secretaria Municipal de Educação (SME) de Canoas. E-mail: valtermorigi@gmail.com

$1>$ A crise do capitalismo é permanente, segundo Mészáros, que mostra que esta crise nada tem de nova. Pelo contrário, é endêmica, cumulativa, crônica e permanente; e suas manifestações são o desemprego estrutural, a destruição ambiental e as guerras permanentes. (MÉSZÁROS, 2009).
} 
Em um projeto que envolve educação e trabalho, é necessário analisar a sociedade e o indivíduo à luz da história que tivemos e temos em nosso país. Afinal, o trabalho é uma criação humana, decorrente de sua relação com o planeta em que habita, como já afirmava Marx.

Antes de tudo, o trabalho é um processo entre o homem e a Natureza, um processo em que o homem, por sua própria ação, media, regula e controla seu metabolismo com a Natureza... Ele põe em movimento as forças naturais pertencentes à sua corporalidade, braços e pernas, cabeça e mãos, a fim de apropriar-se da matéria natural numa forma útil para sua vida. (MARX, 1983, p. 149).

Nas comunidades primitivas, o modo de produção era comunal, tudo era feito em comum, não havia classes sociais nem de trabalho; em seguida, os povos da Antiguidade e, posteriormente, da sociedade na Idade Média, os quais possuíam ainda algumas características da sociedade antiga, já tinham como meio dominante de produção a terra e a forma econômica dominante era a agricultura. O trabalho não se constituía uma esfera separada da vida.

A sociedade moderna contou com uma força destrutiva para seu progresso; foi à invenção das armas de fogo, ou seja, estavam sendo destruídas as formas pré-modernas, e elementos fundamentais do capitalismo passaram a existir porque contaram com a economia militar armamentista.

Para ganhar dinheiro as pessoas passaram a vender sua força de trabalho. Foram rompidas as relações dadas como naturais, com base em laços de sangue em que a nobreza e a servidão eram passadas de pai para filho. Na modernidade capitalista as relações sociais tornam-se mais fluídas, instaura-se uma crítica social com duas vertentes:uma imanente ao sistema, e outra categorial. O capitalismo tinha e tem como meta o lucro, a transformação de dinheiro em mais dinheiro, a criação do valor, que é o elemento fundante do capitalismo.

A qualificação da força de trabalho, ao longo da história do capitalismo, foi definida e construída com base nas necessidades do processo de acumulação capitalista, que é realizado por meio de práticas educativas, segundo a lógica do capital. Nas diversas formas que a organização do trabalho assumiu desde a manufatura, práticas educativas subjacentes sempre estiveram presentes, demarcando um caráter de subordinação e de resistência do homem ao trabalho, a exemplo das práticas que dividiram as formas artesanais de produção, evidenciadas na evolução do processo histórico de expropriação gradativa do trabalhador dos seus instrumentos de trabalho.

Mais tarde, o projeto pedagógico taylorista incorpora à organização do trabalho práticas educativas que visavam a ajustar o trabalhador ao processo de reprodução capitalista, estabelecendo parcelamento e rotinização das operações, controle dos tempos e dos movimentos, seleção e treinamento para postos de trabalho e exigência do envolvimento do indivíduo.

Posteriormente, o fordismo busca aplicar e adaptar de forma mais eficiente as práticas tayloristas, sustentando-se no avanço da mecanização, produção em massa de bens padronizados, persuasão com a oferta de salários mais altos, construindo, assim, a necessidade de formar um "novo homem".

Hoje vivemos numa sociedade capitalista em crise. Nesse cenário, quem acredita na viabilidade de um projeto emancipatório sente-se desafiado a pesquisar e aprofundar a relação educação e trabalho, bem como projetar o futuro desses na vida cotidiana. Em um tempo em que estamos numa sociedade global, em que as fronteiras políticas e geográficas tradicionais se rearticularam, o homem moderno não pensa em uma vida 
além do trabalho ou desvinculada do mesmo. O trabalho passou a ser o centro da vida, obrigando as pessoas a se organizarem em torno dele.

Nós que professamos a esperança de que "um outro mundo é possível”, mantemos a perspectiva da constituição de um sujeito como objetivo, capaz de construir uma sociedade igualitária, criativa, diversa, livre e prazerosa no ócio. Foi somente na sociedade moderna que nasceu a ideia de educação para cidadania, escolarização universal, gratuita e leiga, para todos. Os novos tipos de contratos sociais de trabalho criaram a necessidade de universalização da escola, pois a ciência e o conhecimento básico são necessários para o desenvolvimento das atividades industriais. Saviani assinala que:

[...] É o que por vezes se chama de vínculo entre a escola e os padrões urbanos. Quanto mais avança o processo urbano-industrial, mais se desloca a exigência da expansão escolar. Por aí é possível compreender exatamente por que esta sociedade moderna e burguesa levanta a bandeira da escolarização universal, gratuita, obrigatória e leiga. A sociedade básica deve ser estendida a todos. (SAVIANI, 1993, p. 152).

A escola age então para atender a demanda do capitalismo. Ela socializa os indivíduos, familiarizando-os com os códigos formais integrantes da cultura letrada, capacitando-os para se integrarem ao processo produtivo.

O artigo pretende analisar como a educação trabalha essa questão da relação com o trabalho, bem como verificar a visão que as políticas das cidades tem sobre o tema, uma vez que estamos inseridos num mundo no qual o ócio é condenado e o trabalho é supervalorizado. O trabalho já foi visto como algo desprezível, e, por muitos séculos, foi uma atividade relegada aos considerados inferiores da sociedade. Atualmente, ninguém mais defende o "direito à preguiça" 2 .

\section{A questão do trabalho na atualidade}

O verdadeiro compromisso é a solidariedade, e não a solidariedade com os que negam o compromisso solidário, mas com aqueles que, na situação concreta, se encontram convertidos em "coisas". (FREIRE, 1981, p. 19)

A crise constante no modelo capitalista nos obriga a voltar às velhas questões e exige respostas, sejam estas antigas ou novas, propõem julgamentos diretos. Uma crise só se torna desastre quando respondemos a ela com juízos pré-formados, isto é, com preconceitos. Esta atitude não apenas aguça a crise como nos priva de experimentar outros modos de pensar. Como escreveu Paulo Freire, “[...] mudar é difícil, mas é possível." (FREIRE, 1996, p. 88).

Um dos contrapontos que destaco aqui ao modelo posto é a ideia da Cidade Educadora. Numa situação de transformação profunda, é preciso que os habitantes das do mundo articulem ações e propostas que permitam melhor fazer frente aos novos desafios, dando a todas as pessoas oportunidades de desenvolvimento e crescimento individual e coletivo.

Uma participação efetiva da população nas decisões locais implica um conceito de democracia em que há a necessidade de todos os cidadãos assumirem nova postura, criando o ambiente adequado para o surgimento de uma Cidade Educadora.

Com os processos associativos e cooperativos isto também ocorre, principalmente quando os sentidos da coesão social são apropriados pela lógica do capital que, ao travestir os significados, propõe que cooperar é apenas uma forma de organizar o trabalho.
$2>0$ Direito à Preguiça é um panfleto político escrito por Paul Lafargue que polemiza com as visões liberais, conservadoras e até marxistas do trabalho. Foi publicado no jornal socialista L'Égalité em 1880. À época, em Paris, a jornada de trabalho superava 12 horas diárias (por vezes estendendo-se até 17 horas) Isso ocorria, pois se seguia a doutrina que dizia que o trabalho era algo dignificante e benéfico. $O$ panfleto é polêmico, discute um pecado capital como direito, escolhido de forma proposital como forma de discutir a dominação através da religião, assumindo o trabalhador como uma figura ligada a Deus. Contra essa conviç̧ão muito difundida por diversos escritores, Lafargue denuncia a "santificação" do trabalho debochando dele como um "dogma desastroso". Pode ser encontrado em: <http://www.ebooksbrasil.org/ adobeebook/direitopreguica.pdf>. 


\section{A economia solidária entendida enquanto alternativa e movimento social}

Em todo o mundo, com destaque para a América Latina, os povos vêm resistindo e lutando para construir projetos alternativos baseados na mobilização popular, procurando seguir o exemplo de luta heróica de Cuba, que se constitui num marco histórico da resistência de um povo contra o imperialismo. A América Latina hoje apresenta um novo patamar de autonomia para a luta, impondo alguns limites ao controle político que o imperialismo norte-americano, através de suas agências de inteligência e das burguesias locais associadas, obstina-se em exercer sobre a região.

As possibilidades abertas de avanço da resistência popular na América Latina a um patamar superior de retomada da luta revolucionária no continente, aliadas às necessidades estratégicas do imperialismo em dominar reservas de recursos naturais, como água e petróleo, fazem com que recrudesçam os ataques contra Cuba e o projeto bolivariano de Venezuela e Bolívia.

Para a resistência e superação dos ataques aos processos em curso, é preciso ser capaz de construir relações como estratégia para alcançar os objetivos pretendidos, sejam eles de ordem material ou ideológica. Desde os primórdios da civilização, o homem procurou agrupar-se como forma de sobrevivência e, com a evolução, esses grupos tornaram-se cada vez mais complexos, dando origem a relações amistosas ou conflituosas que se tornaram base do estudo de ciências como a Psicologia e a Sociologia.

A partir das indagações sobre o indivíduo e a formação de grupos, surgiu então uma inquietação maior levando cientistas sociais de diversos países a questionarem o motivo que impulsiona os indivíduos a unirem-se em torno de um objetivo, a movimentaremse em direção a comportamentos coletivos, o que ficou conhecido por teoria da ação social, tornando-se pauta de estudos de vários autores na América do Norte e Europa. Os chamados movimentos sociais surgem fortes e potentes, porém logo aparecem outras formas de organização, incentivadas pelo Poder Público, como atesta Gohn.

os movimentos sociais populares perderam sua força mobilizadora, pois as políticas integradoras exigiram a interlocução com organizações institucionalizadas. Ganham importância as ONGs por meio de políticas de parceria estruturadas com o poder público, que, na grande maioria dos casos, mantém o controle dos processos deflagrados enquanto avalista dos recursos econômicos monetários. (GOHN, 2007, p. 297).

\section{Marco histórico recente no Brasil}

Não basta saber ler que Eva viu a uva. É preciso compreender qual a posição que Eva ocupa no seu contexto social, quem trabalha para produzir a uva e quem lucra com esse trabalho. (FREIRE, 1991, p. 8).

A partir do Fórum Social Mundial em Porto Alegre (2001), movimentos sociais, sindicais, estudantis e grande parte das igrejas tiveram iniciativas de diálogo e aglutinação de suas ações. As agremiações políticas situadas à esquerda, com destaque para o Partido dos Trabalhadores (PT), avançou no desenvolvimento da consciência de que era momento de novas respostas ao neoliberalismo, mais criativas e originais, antes que o capitalismo selvagem tomasse conta do mundo. 
Quando Lula foi eleito presidente pela primeira vez, em 2002, a economia solidária constava em seu programa. Nesta ocasião, duas importantes unidades da federação (UFs) o Rio Grande do Sul governado por Olívio Dutra e a capital de São Paulo por Marta Suplicy - desenvolviam amplos programas de fomento à economia solidária. Nestas condições, a solicitação ao presidente eleito de criar uma Secretaria Nacional de Economia Solidária (SENAES) no Ministério do Trabalho e Emprego (MTE) teve pronta acolhida. Embora a criação tivesse de esperar todo o primeiro semestre de 2003 pela aprovação no Congresso da legislação necessária, a perspectiva de que o governo federal oficializaria o reconhecimento da economia solidária como parte integrante do seu programa social mobilizou o movimento, que iniciou uma série de reuniões nacionais, que culminaram na fundação do Fórum Brasileiro de Economia Solidária (FBES) e da Rede de Gestores Públicos de Economia Solidária na mesma ocasião em que a SENAES abria suas portas no $3^{\circ}$ andar do Bloco F da Esplanada dos Ministérios.

Na primeira gestão do governo de Luiz Inácio Lula da Silva (Lula) aconteceu a implementação da Secretaria Nacional de Economia Solidária (SENAES), ligada ao Ministério do Trabalho e Emprego (MTE) que teve como principal desafio realizar o Programa de Economia Solidária em Desenvolvimento. Este apoio se concretiza a partir da formulação de políticas públicas que atuam na criação de um espaço público favorável ao desenvolvimento da Economia Solidária bem como através da definição de um marco legal que sustente e viabilize tais iniciativas.

Essa nova perspectiva que surgiu através das parcerias com os estados e municípios representou um novo horizonte para as iniciativas cooperativas e associativas de caráter popular solidário visto que antes poderiam estar mais isolados do poder público e agora passam a ser vistas como oportunidades dentro de uma perspectiva de desenvolvimento local.

Trata-se de empreendimentos solidários e a forma como esse apoio é proposto pode vir a influenciar o processo de autogestão, enfraquecendo as bases de sustentação que caracterizam esse tipo de iniciativa. Dessa forma, com um olhar sobre a atuação do poder público enquanto agente na construção de uma identidade coletiva para o Movimento da Economia Solidária e, por outro lado, com um olhar sobre os atores que constroem tal movimento para tanto buscando parcerias com o poder público, desenvolve-se o momento histórico brasileiro acerca dos conceitos da economia solidária.

Conforme o presidente Lula, na cerimônia de entrega do relatório final da II Conferência Nacional de Economia Solidária (CONAES, realizada pelo Conselho Nacional de Economia Solidária, em 17/11/2010): "A Cooperativa não nasce por decreto, nem por lei, ela é um estágio da consciência humana de repartir os ganhos e prejuízos. Leva um tempo para o ser humano saber viver em comunidade."

$\mathrm{Na}$ América Latina e no mundo, a busca pela transformação das relações humanas passa pela aposta em novas organizações de trabalho e educação, novas formas de produção de mercadorias, nas quais a força do trabalho não seja separada do trabalhador que a produz, onde a ideia de economia possa ser colocada ao lado da de solidariedade.

\section{A economia solidária: um conceito em construção}

Não há transição que não implique um ponto de partida, um processo e um ponto de chegada. Todo amanhã se cria num ontem, através de um hoje. De modo que o nosso futuro se baseia no passado e se corporifica no presente. Temos de saber o que fomos e o que somos, para saber o que seremos. (FREIRE, 1981, p. 33). 
Como bem nos lembra Freire, no seu diálogo com Shor, "além de um ato de conhecimento, a educação é também um ato político. É que não há pedagogia neutra” (FREIRE, 1986, p. 25). E, por óbvio, nas cidades há espaço para visualizarmos as relações econômicas entre o modelo tradicional do capitalismo e a nova visão de uma economia solidária, propomos o seguinte quadro comparativo:

\section{Quadro 1: Quadro comparativo entre as relações econômicas}

\begin{tabular}{|l|l|}
\multicolumn{1}{|c|}{ Economia capitalista } & \multicolumn{1}{c|}{ Economia solidária } \\
\hline intercâmbio & solidariedade \\
\hline individualidades & subjetividades, sentimentos, simpatias \\
\hline quantitativas & qualitativas \\
\hline interesse pela mercadoria & interesse pela pessoa \\
\hline transitórias & permanentes \\
\hline $\begin{array}{l}\text { sem esperar alteração } \\
\text { de comportamentos individuais }\end{array}$ & comunitárias, organização, convivência \\
\hline racionalidade comercial & racionalidade humana \\
\hline
\end{tabular}

Fonte: dados da pesquisa, $2013 .^{3}$

Cooperar tem a ver mais do que com intercâmbio de ação, tem a ver com formas solidárias de tomar decisões coletivas, onde os envolvidos, ao estabelecer linguagens e parâmetros comuns, são capazes de dar sentido aos espaços de poder existentes no grupo, levando em consideração os sentimentos e as subjetividades de cada individuo, sem deixar a individualidade predominar.

No entanto é preciso ter presente que a radicalidade da cooperação fica prejudicada ou inviabilizada quando há modos de conviver que privilegiam comportamentos individualistas, egocêntricos, cujos interesses e valores se apresentam como concorrentes e, não raro, abertamente conflitantes, dificultando tomadas de decisões consensuais.

Interessante perceber que os arranjos organizacionais referendados pelas cartilhas neoliberais apresentam a cooperação que é processo coletivo como - ação individual - (“a minha parte eu fiz...”) - incentivando o individualismo como única possibilidade de mudança.

Na América Latina, parte dos processos de cooperação foram sancionados externamente, pela força ou por autoridade de pessoas de referência, porém a sua história destaca que, apesar das suas particularidades, há elementos comuns que parecem indicar que, apesar da exploração e da desigualdade social, sempre existiram estratégias baseadas em modelos de cooperação e ação coletiva para contestar (ou refutar) a dominação.

O sentido do termo "Economia Solidária" ainda é algo relativamente novo, apesar das práticas que a traduzem não serem nada de inédito entre comunidades de países da América Latina e Europa, onde mais se tem observado iniciativas dessa natureza (FRANÇA FILHO, 2006). A novidade está em unificar todas essas práticas em uma só denominação, fazendo com que deixem de existirem isoladas, transformando-se em evidência, agindo contra o comportamento econômico que se baseia estritamente na economia de mercado, desacreditando a possibilidade de uma economia que seja plural como pretende a economia solidária.

$3>$ Quadro criado pelo autor, com base no texto "Economia solidária versus economia capitalista", de Paul Singer, disponível em: <www.scielo. $\mathrm{br} /$ scielo.php?script $=$ sci_arttex $\&$ pi $\mathrm{d}=\mathrm{S} 0102-69922001000100005>$. Acesso em: jun. 2013.
Diversos autores explicam a Economia Solidária a partir da concepção de um novo modo de produção, estando este vinculado a uma estratégia de mercado diferenciada que considere a cooperação, a solidariedade, a criação de redes, a gestão do conhecimento e a autogestão, como forma de desenvolver uma prática de produção e comercialização que difere da lógica vigente no sistema capitalista e que possibilita oportunidade a todos, principalmente àqueles que se encontram à margem do atual sistema. 
As conceituações para o termo Economia Solidária demonstram, principalmente, que este é um processo ainda em construção, sendo alvo de várias percepções que vão desde um novo modo de produção até uma forma de emancipação social.

\section{Economia Solidária como Política Pública}

O caminho trilhado no amadurecimento e na viabilização das utopias sonhadas no campo da economia solidária ainda é pequeno, recente, na medida em que ainda há muito por avançar, em temáticas como: geração de empregos, sustentabilidade, relação com o meio ambiente, monitoramento, controle social, geração de renda e tantas outras.

As políticas públicas disponibilizadas para o segmento da economia solidária precisam ser ampliadas e qualificadas para a melhoria de vida dos indivíduos envolvidos nos diferentes trabalhos e ações criadas a partir, por exemplo, das incubadoras tecnológicas vinculadas às universidades, muito disseminadas nos últimos tempos.

O que temos que ter em mente é que o atraso e a miséria foram criados com descaso de séculos por estruturas de poder que se limitavam à concessão de privilégios para os poucos que detinham o comando. A economia solidária com controle social poderá ser um instrumento de modificação do status quo existente, mas é preciso ter clareza de que não há uma receita pronta, é um constante desafio que precisa ser elucidado e enfrentado pelo conjunto de atores sociais que se propõem a colocar a inteligência, a sensibilidade, a criatividade e a vida na construção de outro mundo possível, mais justo e fraterno.

Um dos grandes desafios que se coloca é o caráter dialético das parcerias, sabendo aplicá-las de forma criativa em cada realidade concreta, não pode ser indicado como a receita universal para todos os empreendimentos de economia solidária, mas a simples possibilidade de acontecer ajuda a manter acesa a chama da crença de construção de um mundo melhor, é uma utopia possível de se concretizar, um caminho que auxilia a vida e a existência de milhões de indivíduos no planeta que não aceitam a imposição do modelo único que os mandatários capitalistas de toda a História sempre oferecem como alternativa aos "esfarrapados do mundo, e aos que nele se descobrem e, assim descobrindo-se, com eles sofrem, mas, sobretudo, com eles lutam.” (FREIRE, 1970, p. 23).

Há relatos significativos de ações concretas que apontam para o desenvolvimento da solidariedade e novas relações da educação com a cidade. Aponto como exemplo as iniciativas seguintes (ver anexo).

\section{Algumas conclusões}

A cidade atual - e sua paisagem ${ }^{4}$ - realiza-se como uma espécie de composição de materiais de texturas variadas, superpostas ou colocadas lado a lado, como imagem a ela associada, misto de tradições locais e referências históricas do lugar. As práticas culturais

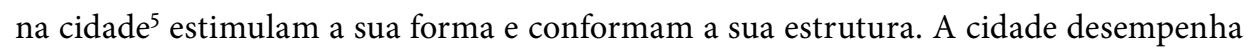
a função clássica de acumulação de capital e de consumo de bens e serviços. Isto leva a dizer que estamos assistindo uma ação sobre o espaço citadino como "experiência vital" e complexa de espaço-tempo, provocando um "turbilhão" que pode anular fronteiras, propiciar aventuras, poder, alegria etc. Assim, a construção do espaço da cidade dar-se-á através da geografia, por entre uma revolução na qual os indivíduos e as comunidades somente poderão construir os locais e os acontecimentos correspondentes à apropriação, não apenas do seu trabalho, mas de sua história. Desse modo, a modernidade que a cidade representa torna-se cultura e lugar de busca da unidade perdida. Nesta busca, a cultura
4 > Trata-se de um conjunto heterogêneo de formas naturais e artificiais, em que predominam estes últimos. Tal heterogeneidade é dada pela multiplicidade e diversidade de usos e funções dos objetos e reflete em boa medida as atividades de diferentes períodos que caracterizaram a vida humana.

5 > A multiplicidade de opções culturais é que tornam as práticas culturais das cidades tão interessantes. Em uma cidade como o Rio de Janeiro, por exemplo, é possível encontrar uma exposição com artefatos do Egito antigo, assistir um espetáculo de ballet clássico no Teatro Municipal, participar de um ensaio de Escola de Samba da Mangueira e visitar um baile Funk na periferia. A existência de diversos museus, teatro e casas de shows, promove uma verdadeira babel cultural. 
da cidade educadora pode servir como elemento coesivo na construção de mudanças necessárias para um mundo do trabalho melhor.

A Educação Popular ligada diretamente a concepção da educação libertadora tem como um dos referenciais, no Brasil, o educador Paulo Freire, um autor que vem embasando o trabalho de educadores/as populares de Porto Alegre. Segundo Zitkoski (2006), Freire está na origem da Educação Popular enquanto paradigma latino-americano. Foi um dos pioneiros a problematizar os desafios concretos que impulsionaram a articulação de lutas organizadas a partir de Movimentos Populares em direção à transformação das realidades sociais opressoras. Nomeada como Práxis Transformadora, os movimentos sociais agrupam inúmeros líderes, intelectuais e educadores/as visando à emancipação social.

Paulo Freire, com sua pedagogia da libertação, valorizava as experiências e o diálogo como princípio político-pedagógico, e é partindo dessa concepção que busca-se pensar em uma Educação para além do Capital (MÉSZÁROS, 2009). Assim, a experiência da prática educativa deve ser contributiva na elaboração de políticas para formação de Educadores/ as Populares que busque a emancipação humana. A construção de uma pedagogia "para além do capital" deve surgir como possibilidade de superação das desigualdades que leva a exclusão social, pois uma educação que está a favor da humanização trabalha para a construção do exercício da conscientização a partir da participação. Como o mestre Paulo Freire alertava, precisamos ter sonhos para impulsionar a busca pelas mudanças:

Não há mudança sem sonho, como não há sonho sem esperança. Por isso, venho insistindo [...] que não há utopia verdadeira fora da tensão entre a denúncia de um presente tornando-se cada vez mais intolerável e o anúncio de um futuro a ser criado [...]. A utopia implica essa denúncia e esse anúncio [...] A nova experiência de sonho se instaura, na medida mesma em que a história não se imobiliza, não morre. Pelo contrário, continua. (FREIRE, 1997b, p. 47).

Assim, a luta pela construção de "inédito-viáveis" tem pautado-se a partir da leitura dessas diferentes realidades, cujas interpretações, reconstruções coletivas e contextualizadas tornam-se compromisso político e pedagógico na construção de sonhos possíveis, entendendo que a tarefa do/a educador/a popular é o de desenvolver novas possibilidades, pedagogias e práticas, negando, assim o "blábláblá autoritário e sectário" (FREIRE, 1997b, p. 20) do discurso neoliberal e fatalista daqueles que desacreditam na transformação e na esperança.

Cabe a todos nós latinos americanos assumidos como sonhadores e utópicos levar adiante a luta pela implementação de políticas públicas que dignifiquem a vida, transformando o trabalho como um momento existencial de realização do ser humano e não aceitar a exploração e a mais-valia que o sistema capitalista nos impõe e faz acreditar que é o único modelo possível. Há possibilidades diferentes, alternativas como a citada aqui da Economia Solidária, e outras mais que nossa intelectualidade precisa ajudar a buscar, pois repito o que já foi escrito no texto, "um novo mundo é possível".

Uma educação humanista, que valorize o ser humano, o indivíduo que traz consigo um saber adquirido na vida e pensa no coletivo no qual está inserido, trabalha a emancipação, a educação para toda a vida, uma cultura de participação social e valorização da pessoa, caminhando para a opção de que a educação pode sim estar a serviço de construir esse novo mundo possível, buscando como caminho a economia solidária, construída como organização coletiva de trabalho, desenvolvendo uma nova forma de buscar a construção do conhecimento, integrando conhecimento e prática, buscando a superação das formas hierárquicas da educação que são reproduzidas nas famílias e escolas, bem como nos espaços tradicionais de trabalho. 


\section{Referências}

BERTRAND, Olivier. Educação e Trabalho In: Delors, Jacques. A educação para o século XXI. Porto Alegre: Artmed, 2005.

BRANDÃO, Carlos Rodrigues (Org.). A Questão Política da Educação Popular. São Paulo: Brasiliense, 1985.

.Educação Popular. 3. ed. São Paulo: Brasiliense, 1986.

BRASIL. Ministério do Trabalho e Emprego. Programa Economia Solidária em Desenvolvimento. Disponível em: <www.mte.gov.br/ecosolidaria>. Acesso em: 25 jan. 2007.

COHN, Amélia. Os governos municipais e as políticas sociais. In: SOARES, José Arlindo; CACCIA BAVA, Silvio. (Org.). Os desafios da gestão municipal democrática. São Paulo: Cortez, 1998.

GAIGER, Luis Inácio. A Economia Solidária diante do modo de produção capitalista. Leituras Cotidianas, n. 127, Rio de Janeiro, 2005.

A Economia Solidária e Espaço Público. In: FRANÇA FILHO et al. (Org.). Ação Pública e Economia Solidária: uma perspectiva internacional. Porto Alegre: Editora da UFRGS, 2006.

GOHN, Maria da Glória. Teoria dos Movimentos Sociais: paradigmas clássicos e contemporâneos. 6. ed. São Paulo: Edições Loyola, 2007.

FORUM BRASILEIRO DE ECONOMIA SOLIDÁRIA. Sobre o FBES. Disponível em: <www.fbes. org.br>. Acesso em: 28 mar. 2008.

FRANÇA FILHO, Genauto Carvalho. A perspectiva da Economia Solidária. In: FISCHER, Tânia. (Org.) Gestão do desenvolvimento e poderes locais: marcos teóricos e avaliação. Salvador: Casa de Qualidade, 2002.

FRANÇA FILHO, Genauto Carvalho; LAVILLE, Jean- Louis. A Economia Solidária: uma abordagem internacional. Porto Alegre: Editora da UFRGS, 2004.

FRANÇA FILHO, Genauto Carvalho et al. (Org.). Ação Pública e Economia Solidária: uma perspectiva internacional. Porto Alegre: Editora da UFRGS, 2006.

FREIRE, Paulo; SHOR, Ira. Medo e Ousadia: O Cotidiano do professor. Rio de Janeiro: Paz e Terra, 1986 .

FREIRE, Paulo. Educação e Mudança. São Paulo: Paz e Terra, 1981.

. Educação na Cidade. São Paulo: Cortez Editora,1991.

. Pedagogia da Esperança: um reencontro com a pedagogia do oprimido. São Paulo: Paz e Terra, 1992 .

Pedagogia da Autonomia, São Paulo: Paz e Terra, 1996.

Pedagogia do Oprimido. Rio de Janeiro: Paz e Terra, 1970

MARX, Karl. Trabalho assalariado e capital. Rio de Janeiro: Editorial Vitória, 1963.

. O Capital. São Paulo: Abril Cultural, 1983. v. 1, t. 1.

MÉSZAROS, István. A crise estrutural do capital. São Paulo: Boitempo, 2009.

SAVIANI, Demerval. Escola e democracia. Campinas, São Paulo: Editora Autores Associados, 1993.

SINGER, P. Introdução à Economia Solidária. São Paulo: Fundação Perseu Abramo, 2002.

STRECK, Danilo R.; REDIN, Euclides; ZITKOSKI, Jaime. (Org.). Dicionário Paulo Freire. 2 ed. Belo Horizonte: Autêntica Editora, 2008 e 2010. . Paulo Freire e a Educação. Belo Horizonte: Autêntica Editora, 2006. 


\section{Anexo}

\section{Observatorio Municipal de Igualdad de Oportunidades de la Ciudad de Albacete}

El Observatorio Municipal de Igualdad de Oportunidades de la Ciudad de Albacete es un instrumento técnico de la Administración Local.

Su objetivo general es analizar y evaluar la situación de igualdad de oportunidades en el municipio de Albacete, identificar desequilibrios existentes y proponer medidas de actuación. Para lograr este objetivo general, se llevan a cabo los siguientes objetivos específicos:

"Identificar las situaciones de desigualdad social.

»Cuantificar las situaciones de desigualdad social mediante:

» La realización de proyectos de investigación social sobre igualdad y exclusión social en Albacete.

" La recogida y análisis de la información disponible en diferentes fuentes.

"Evaluar las situaciones de desigualdad social y las políticas correctoras aplicadas.

»Difundir las investigaciones y datos a la sociedad en general y especialmente, a los sectores sociales más implicados en la lucha contra la exclusión social. Además, se plantea la creación de un Centro de Documentación sobre Igualdad.

" Proponer líneas de trabajo que permitan atajar las situaciones de desigualdad y establecer políticas correctoras.

El Observatorio Municipal de Igualdad de Oportunidades de Albacete es una herramienta que aspira a contribuir a una mayor igualdad entre las personas que viven en Albacete en términos de ciudadanía, independientemente de su sexo, edad, procedencia étnica, religión, etc.

El trabajo del Observatorio se enfoca con dos perspectivas que se complementan; por un lado la investigación en sí misma y por otro la evaluación de las políticas públicas, ya que la labor del Observatorio es analizar la situación de la ciudad y comprobar si las políticas que se llevan a cabo son realmente efectivas y contribuyen a una mayor igualdad para los ciudadanos.

El Observatorio de Igualdad de Oportunidades se basa en una serie de principios:

" Igualdad: Los principales factores de desigualdad (clase social, género, procedencia étnica) se incluyen transversalmente en los estudios realizados por el Observatorio.

» Solidaridad: El análisis social no es un fin en sí mismo, sino un paso en un proceso de concienciación social y solidaridad entre actores sociales.

» Participación: Se establecen mecanismos de cooperación en tres niveles complementarios:

"Servicios del Ayuntamiento.

»Instituciones Públicas de Albacete.

» Resto de agentes sociales.

" "Administración cercana": Se trabajará desde los criterios de transparencia (difusión pública), calidad (atención integral) y eficacia (adecuación entre necesidades, objetivos y diseño de programas). 


\section{Programa Crédito Popular Solidário - São Paulo - Brasil}

Ser referência no setor de microfinanças, contribuindo para o desenvolvimento das atividades econômicas e sociais do município de São Paulo de forma sustentável.

No Brasil, 13 milhões de pequenos empreendimentos (98,5\% das empresas do país) são responsáveis por mais de $60 \%$ dos empregos e ocupações gerados e por $8 \%$ do PIB. 8,5 milhões destes empreendimentos são constituídos por micro e pequenos negócios informais, produto da capacidade empreendedora brasileira e da busca da sustentabilidade econômica das pessoas e das comunidades.

8 milhões destes empreendimentos (60,6\% das empresas do país) não têm acesso ao sistema oficial de crédito, sobretudo financiamento à produção.(fonte: SEBRAE)

Imagine o sonho de poder contribuir para mudar esta realidade!

Imagine o sonho de ter como missão trabalhar a inclusão social efetiva, proporcionando acesso ao crédito pela população de baixa renda.

Imagine o sonho de ser um agente de transformação da realidade social, contribuindo para o desenvolvimento destes pequenos empreendedores, fortalecendo os mercados locais e alavancando a geração de atividades produtivas, renda e empregos.

A Organização Cidadã Crédito Popular Solidário - São Paulo Confia ${ }^{6}$ foi concebida com foco neste sonho, com a missão de ofertar crédito produtivo e orientado a empreendedores formais e informais. Nosso objetivo é a inclusão social através da geração de empregos, renda e solidariedade, materializando com atitude a sustentabilidade de um programa específico de microcrédito que tem como estratégia a inserção da entidade no mercado de microfinanças.

Constituída como uma Organização da Sociedade Civil de Interesse Público (OSCIP) desde 2001, a São Paulo Confia é pioneira em São Paulo na aplicação de um Programa de Microcrédito Produtivo e Orientado. Esta modalidade de crédito tem despertado atenção do mundo pelo impacto comprovadamente positivo no desenvolvimento dos países e na vida das pessoas.

A entidade é um exemplo vivo de como instituições públicas e privadas e as organizações da sociedade civil podem se unir com o objetivo de combater a pobreza e dar condição e vazão à capacidade empreendedora da nação, ofertando melhores condições de vida, gerando atividades produtivas, renda, emprego e sustentabilidade sócio-econômica.

A formação desta parceria público-privada, com a participação das organizações da sociedade civil, é estratégica na formulação e aprovação das políticas de crédito, na articulação social de ações ligadas ao microcrédito e na captação e política de alocação do funding do Programa.

O grande diferencial do Programa de Microcrédito Produtivo e Orientado da São Paulo Confia é a sua metodologia, baseada no relacionamento direto do agente de crédito com os empreendedores no local da sua atividade. O agente é treinado para orientar o empreendedor sobre a gestão do negócio, as suas necessidades de crédito, a definição do valor do empréstimo necessário para o desenvolvimento sustentável do negócio, sobre as reais condições de tomada de crédito após a avaliação da atividade e da capacidade de endividamento do empreendedor.

Desta forma, este acompanhamento personalizado dos agentes de crédito contribui para um preparo melhor dos empreendedores, que integram o mercado na gestão de seus negócios de forma mais competitiva e sustentável, garantindo o retorno dos créditos concedidos (adimplência) e o desenvolvimento local. O acompanhamento é feito durante todo o período da operação.
$6>0$ programa São Paulo Confia gera lucro líquido para os microempreendedores e reda para as famílias envolvidas, aumentando o número de produtos que comercializam, modificando a situação de renda dessas famílias, levando algumas a superar a saída da linha de pobreza. 
As operações de crédito são feitas sem a exigência de garantias reais, que é substituída por outra forma alternativa e adequada, o aval solidário (grupo solidário), onde o grupo se responsabiliza mutuamente pelo pagamento integral dos empréstimos (daí o termo "solidário"), facilitando o acesso a um maior número de pessoas que não têm condições de participar das linhas de crédito do sistema financeiro tradicional, inclusive aquelas que estão em situação de restrição cadastral (bancarização).

A formação e a expertise da São Paulo Confia, a solidez de seu embasamento metodológico, os resultados alcançados ao longo dos últimos 5 anos e o controle da adimplência por pilares de gestão operacional bem consolidados têm sido fatores avaliados/auditados por um número cada vez mais amplo de empresas/instituições. Em 2005 podemos destacar dois novos parceiros agregados, um convênio com a Caixa Econômica Federal (CEF) e um aporte inicial do Banco Nacional de Desenvolvimento Econômico e Social (BNDES) no valor de 1,7 milhões de reais. Como reconhecimento ao trabalho desenvolvido, a São Paulo Confia foi a vencedora do Prêmio Betinho de Cidadania 2005.

Extraído de: "Nossa visão".

Disponível em: <http://www.saopauloconfia.org.br/>.

Acesso em: 16 abr. 2011. 